This item was submitted to Loughborough's Research Repository by the author.

Items in Figshare are protected by copyright, with all rights reserved, unless otherwise indicated.

\title{
Performance of amorphous silicon double junction photovoltaic systems in different climatic zones
}

PLEASE CITE THE PUBLISHED VERSION

http://dx.doi.org/10.1109/PVSC.2002.1190947

PUBLISHER

(C) IEEE

VERSION

VoR (Version of Record)

LICENCE

CC BY-NC-ND 4.0

\section{REPOSITORY RECORD}

Gottschalg, Ralph, Christian N. Jardine, R. Ruther, Thomas R. Betts, G.J. Conibeer, J. Close, David Infield, et al.. 2019. "Performance of Amorphous Silicon Double Junction Photovoltaic Systems in Different Climatic Zones”. figshare. https://hdl.handle.net/2134/8193. 
This item was submitted to Loughborough's Institutional Repository (https://dspace.lboro.ac.uk/) by the author and is made available under the following Creative Commons Licence conditions.

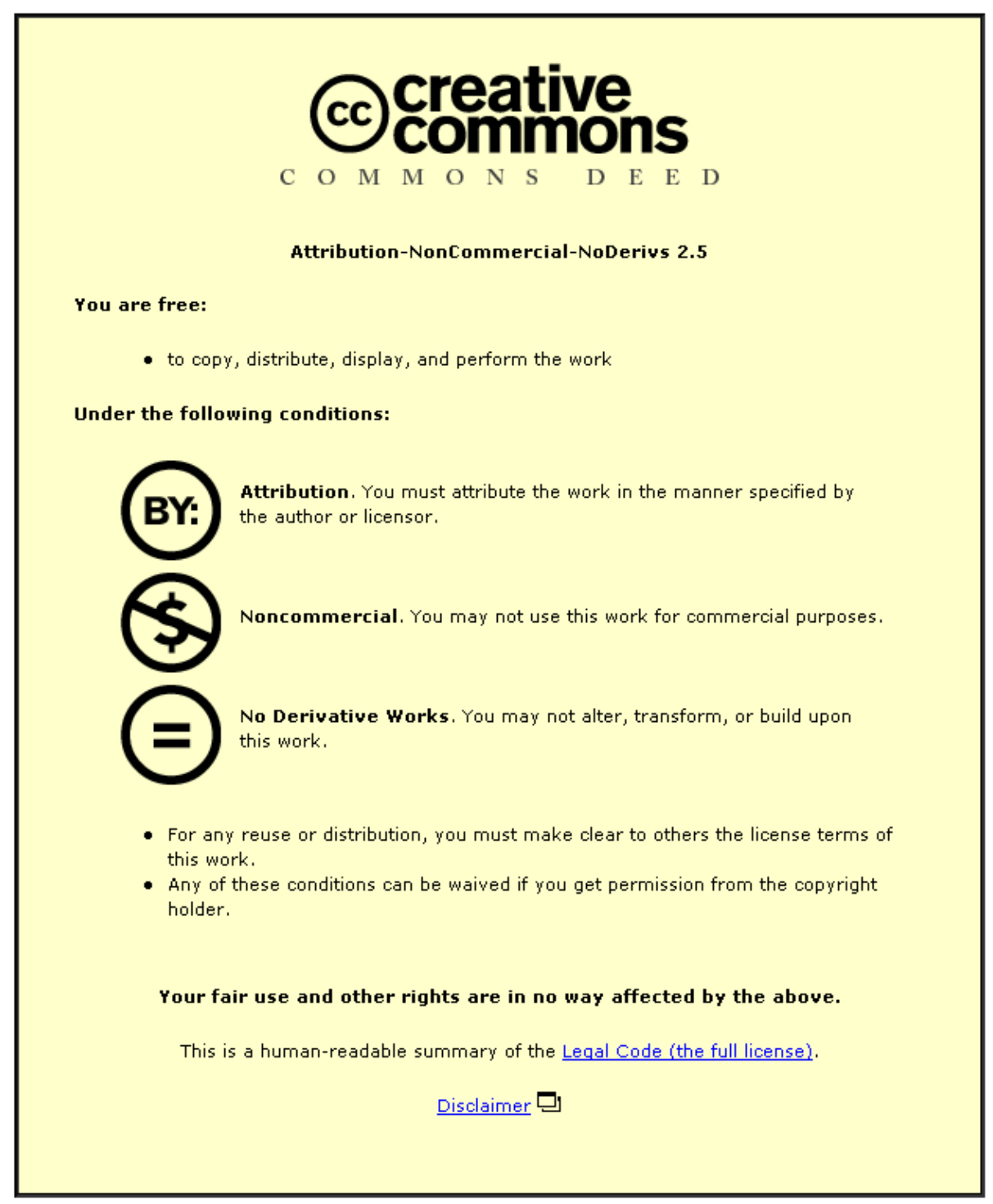

For the full text of this licence, please go to: http://creativecommons.org/licenses/by-nc-nd/2.5/ 


\title{
PERFORMANCE OF AMORPHOUS SILICON DOUBLE JUNCTION PHOTOVOLTAIC SYSTEMS IN DIFFERENT CLIMATIC ZONES
}

\author{
R. Gottschalg ${ }^{1}$, C.N. Jardine ${ }^{2}$, R. Rüther ${ }^{3}$, T.R. Betts ${ }^{1}$, G.J. Conibeer ${ }^{4}, J^{\prime}$ Close $^{5}$, D.G. Infield', M.J. Kearney ${ }^{1}$, \\ K.H. Lam ${ }^{5}$, K. Lane ${ }^{2}$, H. Pang ${ }^{5}$, R. Tscharner ${ }^{6}$ \\ 1 Centre for Renewable Energy Systems Technology, Loughborough University, Loughborough, LE11 3TU \\ ${ }^{2}$ Environmental Change Institute, Oxford University, 5 South Parks Road, Oxford, OX1 3UB, UK \\ ${ }^{3}$ Labsolar, Universidade Federal de Santa Catarina, Caixa Postal 476, Florianopolis - SC 88040-900, Brazil \\ ${ }^{4}$ Photovoltaics Special Research Centre, University of New South Wales, Sydney NSW 2052, Australia \\ ${ }^{5}$ The University of Hong Kong, Pokfulam Road, Hong Kong, China \\ ${ }^{6}$ Institut de Microtechnique, University Neuchâtel, Breguet 2, CH-2000 Neuchâtel, Switzerland
}

\begin{abstract}
To date the majority of investigations into the performance of amorphous silicon photovoltaic systems have been limited to single sites, and therefore the conclusions from such studies are unlikely to be as generic as they might at first appear. This paper compares data collected from different systems across the world in Brazil, Hong Kong, Spain, Switzerland, and the United Kingdom. All systems have been operating for a number of years, and are employing double junction amorphous silicon devices of a similar age manufactured by RWE Solar.

The data are analysed for performance variations reflecting the different climatic zones, and the variations are explained on the basis of operating temperature, incident irradiation and seasonal spectral shift.
\end{abstract}

\section{INTRODUCTION}

Recent times have seen the increased introduction of thin film amorphous silicon (a-Si) photovoltaic systems. The seasonal performance of these devices is markedly different from devices employing the more common crys- talline silicon technology. The maximum efficiency occurs during summer, rather than winter, see e.g. [1]. This effect can, in some climates, be attributed almost entirely to variation in the incident solar spectrum $[2,3]$. Other researchers have, we believe wrongly, attributed this effect exclusively to a seasonal recovery pattern [4]. This improved summer performance is clearly of interest when investigating the energy yield of these devices and judging their quality. Previous investigations have often been hampered in that they were based on measurements at only one location. In this work, a number of systems from a single manufacturer (RWE Solar, Division Phototronics) are compared. A wide variety of climatic conditions are covered in this study by analysing data from sites as widely located as Brazil, Hong Kong, Spain, Switzerland, and the United Kingdom.

\section{SYSTEMS UNDER INVESTIGATION}

The five systems under investigation are summarised in Table 1. Some of these are in fact sub-systems of a larger installation. Sub-arrays with non-optimal roof pitches, and those producing unreliable data have been neglected.

It can be seen that a wide variety of operational con-

\begin{tabular}{|c|c|c|c|c|c|}
\hline System & 1 & 2 & 3 & 4 & 5 \\
\hline Location & Florianopolis & Hong Kong & Mallorca & Neuchâtel & Oxford \\
\hline Country & Brazil & China & Spain & Switzerland & UK \\
\hline Environment & $\begin{array}{l}\text { sub-tropical, south } \\
\text { American } \\
\end{array}$ & $\begin{array}{l}\text { sub-tropical, } \\
\text { East Asia }\end{array}$ & $\begin{array}{l}\text { Mediterranean, } \\
\text { south European }\end{array}$ & $\begin{array}{l}\text { alpine, } \\
\text { central European }\end{array}$ & $\begin{array}{l}\text { maritime, } \\
\text { north European }\end{array}$ \\
\hline Longitude ["] & $48 \mathrm{~W}$ & $113 \mathrm{E}$ & $3 \mathrm{E}$ & $7 E$ & $1 \mathrm{~W}$ \\
\hline Latitude [1] & 275 & $22 \mathrm{~N}$ & $39 \mathrm{~N}$ & $47 \mathrm{~N}$ & $52 \mathrm{~N}$ \\
\hline Start of operation & $16 \operatorname{Sep} 1997$ & 01 Oct 2000 & 01 Oct 1999 & 10 Oct 1996 & $01 \mathrm{Jul} 2000$ \\
\hline $\begin{array}{l}\text { Installed Capacity } \\
{\left[W_{0}\right]}\end{array}$ & 512 & 2400 & 576 & 6440 & 576 \\
\hline Orientation [ EoS] & 174 & -85 & -15 & 25 & -5 \\
\hline Inclination [4] & 27 & 90 & 25 & 33 & $\sqrt{13}$ \\
\hline Inverter & WE 500 NWR & Solwex 3090 & NKF OKE4 & TOPCLASS $2500 / 4$ & NKF OKE4 \\
\hline Modules & PM6008A36N & PM6008A36N & 30DG-UT & PM6008A068 & 30DG-UT \\
\hline Installation & \begin{tabular}{|l} 
Shading \\
\end{tabular} & Façade & Roof-top & Roof-top & Roof-top \\
\hline Sampling Interval & $4 \mathrm{~min}$ & $10 \mathrm{sec}$ & $30 \mathrm{~min}$ & $10 \mathrm{~min}$ & $30 \mathrm{~min}$ \\
\hline
\end{tabular}

Table 1. Overview of the systems under investigation. 
ditions are covered by the systems under investigation. The climatic conditions and solar path in Fiorianopolis and Hong Kong are comparable, though one is southem hemisphere and the other is northern. The three European systems vary climatically due to sea exposure, of a Mediterranean infuence, (Mallorca) and northern maritime climate, (Oxford) or land mass and high altitude, (Neuchâtel). Their different latitudes account for distinct seasonal differences, varying day-length through the year and the different angle and altitude of the sun's path. For both Hong Kong and Florianopolis, the peak summer solar radiation is directly overhead benefiting roof applications and penalising façade installations.

All systems are building integrated, either as façades (Hong Kong), as shading devices (Florianopolis) or as rooftop systems (Neuchâtel, Mallorca, Oxford). The cormmon factor for all devices is the use of RWE Solar double junction (pin-pin, same bandgap) devices, thus differences due to different manufacturing technology are minimised. The 32Wp RWE Solar a-Si modules for gridconnected applications are offered in either $36 V_{D C}$ or $68 V_{D C}$ models, depending on whether the individual solar cells are patterned length-wise (less celts, thus $V_{O C}=$ $36 \mathrm{~V}$ ), or width-wise (more cells, $V_{O C}=68 \mathrm{~V}$ ). The details of each installation is reported elsewhere, see [5] for the Florianopolis system, [6] for the Hong Kong system, [7] for the Mallorca and Oxford systems and [B] for the Neuchâtel system.

The oldest system is the one at Neuchatel, which started operating in October 1996. The Florianopolis system started operation in September 1997 and the remaining systems in 1999 and 2000. There systems use different inverters, so this analysis concentrates on DC data as much as possible. There still is, however, an issue with possible sub-optimal maximum power point tracking of the systems adversely affecting the output of the arrays.

Whilst the technology is the same at each site, the difference in performance of the systems becomes apparent by examining the amount of time spent at different irradiance levels, as shown in Fig. 1. This difference is the major influence on the energy yields of these systems.

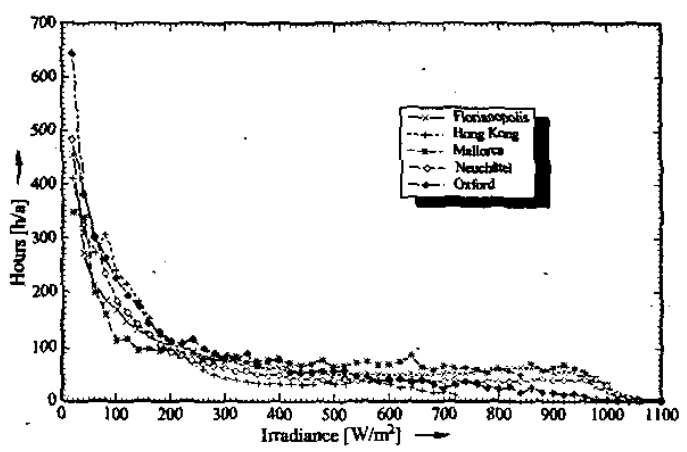

Fig. 1. Histogram of intensities at the different locations.

It is clear from Fig. 1 that the system in Oxford operates for longer than any of the other arrays at low light intensities and does not experience higher irradiance lev- els. This is because this array experiences the largest average air mass of all the systems, and the highest degree of cloud cover. The lack of very high irradiances in Hong Kong is due to its vertical inclination, which is not optimally inclined for absorption of peak sunshine. The Mallorca system receives the highest energy. The Oxford and the Mallorca systerns tend to slightly underestimate high irradiances due to the relatively long sampling time of $30 \mathrm{~min}$.

\section{DATA TREATMENT}

All monitoring data were added to a database. The data manipulation was carried out using the same queries in all cases, ensuring a consistent analysis.

The influence of temperature and irradiance is investigated by sorting all available data into irradiance bins of $20 \mathrm{Wm}^{-2}$ and temperature bins of $1^{\circ} \mathrm{C}$. The duration of time spent in each bin was summed for each site. Data were summed over the maximum number of whole years allowed by the size of dataset (e.g. Mallorca for 2 years from 01/01/00 - 31/12/01), and data was then normalised by the number of years to give a histogram of annual irradiance. Those sites that have been operational for longer, and those with shorter sampling times, such as Florianopolis, show less statistical scatter. The average daily yield was calculated in two stages. First, daily specific yields were calculated for each day at each site. Then average daily specific yields were calculated, by averaging all the daily specific yields in a given month.

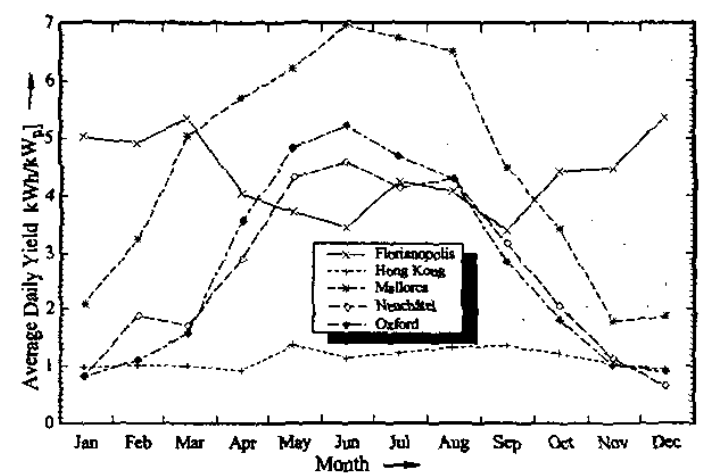

Fig. 2. Seasonal variation of average daily yield.

\section{RESULTS}

All systems exhibit a seasonal variation of the energy yield, as illustrated in Fig. 2 , where the average daily yield is illustrated for all systems. The Mallorca system outperforms the other systems, as it receives the greatest annual in-plane irradiance - a consequence of both climate and its optimal orientation. Conversely, the low yield of the Neuchâtel and Hong Kong system is purely due to their sub-optimal orientations. In particular, the vertical façade of the Hong Kong system deviates significantly from its ideal inclination.

It is interesting to see that, with the exception of the Neuchattel and Hong Kong systems, the magnitude of the 
seasonal yield difference is approximately linear with the distance of the system from the equator. The minimum of the yield for the Florianopolis system is in June, as is expected for a system in the Southern Hemisphere.

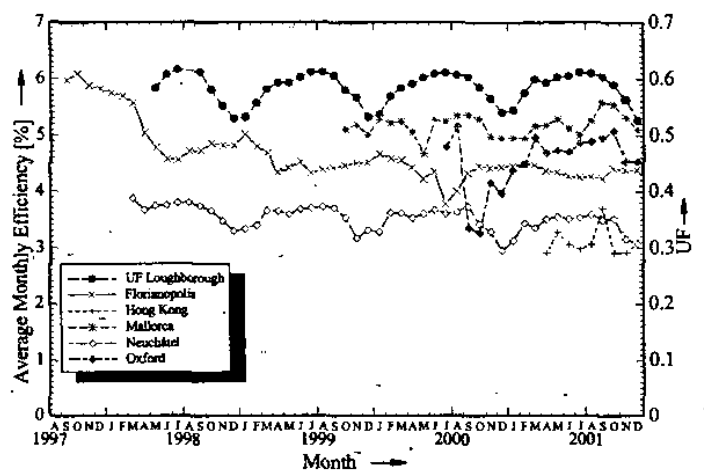

Fig. 3. Variation of the monthly efficiency.

Obviously, the magnitude of the irradiance is crucial when looking at the daily yield. The picture changes slightly when looking at the behaviour of the monthly average system efficiency, as shown in Fig. 3. There is a seasonal trend observable for all devices, again with Florianopolis exhibiting a minimum when the other systems exhibit a maximum. The drop in efficiency for the Oxford system in the initial months is due to some teething problems with the data acquisition equipment. All systems exhibit a relatively stable operation after the initial degradation (as far as the degradational period was monitored). The difference in magnitude is due to different production periods and different orientations, which shows in the Neuchâtel system, as this system is split into one east, one west and one south facing aspect. It is, however, interesting to see that the seasonal variation of the systems in Europe follows the trend in the useful fraction (UF), which we define as the fraction of irradiance in the spectrally useful range of the device with respect to the global irradiance. This indicates that the overall seasonal variation is nearly exclusively caused by spectral effects.

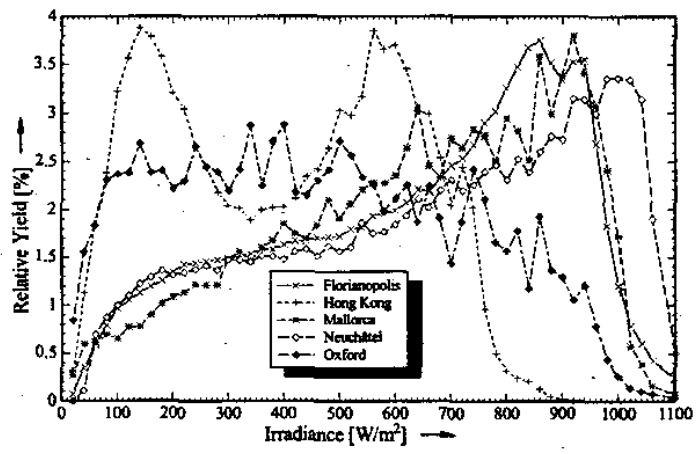

Fig. 4. Relative yield versus irradiance.
The absolute loss in efficiency due to degradation appears to be in the range of $20 \%$ of its initial value. This was, however, mostly accounted for in the initial system design. One should not forget that this is the average monthly efficiency, and not the instantaneous efficiency at STC. Thus, e.g. in the case of the Florianopolis system which has a name plate efficiency of five percent, the performance ratio is higher than $85 \%$, which is impressive considering that it is a warm and humid operating environment and the age of the system.

The difference of the operating environments becomes very apparent when investigating how much of the energy is generated in certain operating conditions. The percentage of the annual yield in a given irradiance bin is given in Fig. 4.

A - significant difference is observed between the Hong Kong and Oxford systems and the remaining systems. The Oxford system generates a significant amount of its energy at low intensities. This effect is a direct result of the high percentage of low irradiance operation shown in Fig. 1. The shape of the results of the Hong Kong system is due to the relatively steep angles of incidence of the irradiance and thus a significant amount of reflection can be expected. Furthermore, as this system is hardly operating at high intensities, the low energy part is emphasised. The Mallorca system produces a slightly higher percentage of its energy at irradiances around the 500 $\mathrm{W} / \mathrm{m}^{2}$ range, while the Florianopolis system produces more at higher irradiances. This behaviour is partially due to a slightly different variation of the system efficiency with irradiance, as illustrated in Fig. 5.

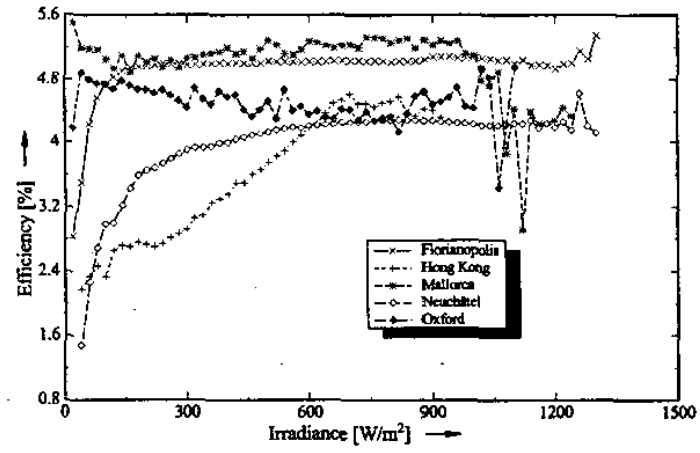

Fig. 5. Influence of irradiance on efficiency.

On the extremes, the Mallorca system shows an increase in operating efficiency for low irradiance levels, whilst the Florianopolis system exhibits a decrease. This can be due to different operating conditions, such as incident useful irradiance. A typical example of this might be an increased diffuse component in overcast, low irradiance conditions that typically would cause the light to be bluer. All systems show that towards higher irradiance levels, there is not a significant influence of irradiance level on the system efficiency. The Oxford system is slightly scattered at high irradiance but this is a statistical effect due to the relatively small data set. In fact, the 
Florianopolis system and the Mallorca system exhibit a nearly identical behaviour despite their different locations.

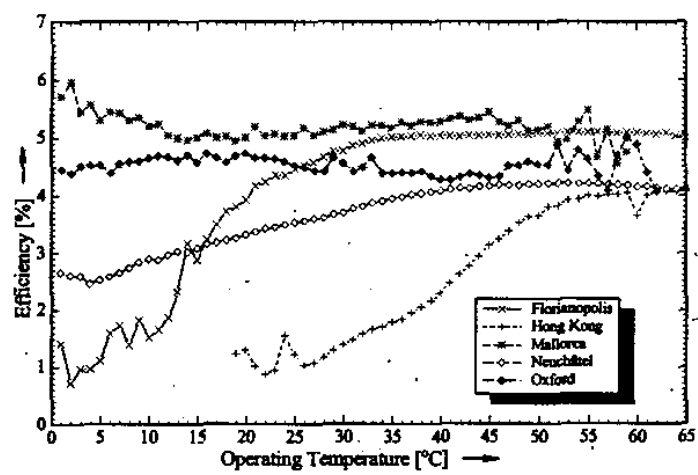

Fig. 6. Influence of operating temperature on efficiency.

The systems show, however, significantly different behaviours when looking at the temperature response, as shown in Fig. 6. The thermal coefficient appears to depend on the operating temperature. This is, however, not a thermal effect. Instead, this is due to the increase in irradiance responsible for this increase in operating temperature. The Hong Kong system confirms this with the efficiency still rising despite operating temperatures of up to $70^{\circ} \mathrm{C}$.

All systems, except for the sub-optimally orientated Hong Kong system, show exceptionally good performance ratios, as shown in Table 2. The lower yielding Neuchatel system, still operating above $75 \%$, is not ideally placed and thus may suffer from high reflection losses: Furthermore, the Neuchatel system is the oldest system in this investigation.

\begin{tabular}{|l|c|c|c|c|}
\hline Location & $\begin{array}{c}\text { Lat } \\
\text { Florianopolis }^{\circ}\end{array}$ & $\begin{array}{c}\text { Energy Yield } \\
{[\mathrm{kWh} / \mathrm{kWpl}}\end{array}$ & $\begin{array}{c}\text { Irradiance } \\
{\left[\mathrm{kWWh}^{\circ} \mathrm{S}\right.}\end{array}$ & $\begin{array}{c}\mathrm{PR} \\
{[\%]}\end{array}$ \\
\hline Hong Kong & $22^{\circ} \mathrm{N}$ & $441^{*}$ & 1497 & 86 \\
\hline Mallorca & $39^{\circ} \mathrm{N}$ & 1669 & 1715 & 68 \\
\hline Neuchátel & $47^{\circ} \mathrm{N}$ & 989 & 1305 & 76 \\
\hline Oxford & $52^{\circ} \mathrm{N}$ & 927 & 1041 & 89 \\
\hline
\end{tabular}

*1. April 2001-31 March 2001

Table 2. Comparison of energy yield and performance ratio.

\section{CONCLUSIONS}

It has been shown that amorphous silicon systems operating in different climatic conditions can exhibit very high performance ratios, despite the often hot conditions and high levels of irradiance. The importance of effective low irradiance operation as well as good thermal stability is clearly demonstrated, as in some climates that contributes significantly to the overall energy production. It is also likely that the observed seasonal performance pattern is largely cause by variations in the incident spectrum rather than seasonal annealing. This paper concentrates on the energy production of the systems, future work will also Include effects of these different environments on the degradation of these devices.

\section{ACKNOWLEDGEMENTS}

The work at CREST has been supported by the Engineering and Physical Sciences Research Council (EPSRC) of the United Kingdom through contract No. GR/N04232. R. Rüther wishes to acknowledge with thanks the Alexander von Humboldt Foundation for sponsoring the Florianopolis PV installation. The array at HK was constructed with funding from the Hongkong Electric Company Limited and Flourcity Architectural Metals Asia. The PV-Compare project, studying the Oxford and Mallorcan test sites, was funded by Solar Century, the BOC Foundation and the Charterhouse Foundation. Data collection at the Mallorcan site was undertaken by Nadav Voloj-Soffer and funded by the Avina Foundation.

\section{REFERENCES}

[1] R. Rüther and J. Livingstone, "Seasorial Variations in Amorphous Silicon Solar Module Outputs and Thin Film Characteristics", Solar Energy Materials and Solar Cells. 36, 1994, pp. 29-43.

[2] Y. Hirata and T. Tani, "Output Variation of Photovoltaic Modules with Environmental Factors - I. The Effect of Spectral Solar Radiation on Photovoltaic Module Output", Solar Energy 55, 1995, pp. 463-468.

[3] R. Gottschalg, D.G. Infield and M.J. Keamey, "Influence of Environmental Conditions on Outdoor Performance of Thin Film Devices", Seventeenth EU PVSEC, 2001.

[4] G. Kleiss, A. Raicu and K. Bücher, "TemperatureDependent Influence of a-Si:H Cell Degradation on the Energy Delivered Under Realistic Reporting Conditions", Twenty-third IEEE PVSC, 1993, pp. 896-900.

[5] R. Rüther. "Experiences and Operational Results of the First Grid-Connected Building-Integrated, Thin Film Photovoltaic Installation in Brazil". Fifteenth EUPVSEC, pages

[6] K. Lam, J. Close and E. Lo, "Construction of Two 25m Tall Vertical Arrays With 2nd Generation Amorphous Silicon Photovoltaic Technologies", Seventeenth EU PVSEC, 2001

[7] C. Jardine, G. Conibeer and K. Lane, "PVCOMPARE: Direct Comparison of Eleven PV Technologies at Two Locations in Northern and Southem Europe", Seventeenth EU PVSEC, 2001

[8] R. Tscharner and A. Shah, "Performance of the Roof Integrated Amorphous Silicon Plant IMT Neuchâtel", Seventeenth EU PVSEC, 2001 